HTS applications will come to market? Had this been written by American or Japanese authors, there might have been a greater discussion of HTS applications (though these do figure strongly in the 250-page section on power applications). But it is as a snapshot of what today's LTS-based industry makes magnetic resonance imaging magnets, particle accelerators and various sorts of laboratory magnets - that the handbook excels.

The handbook can be profitably studied to understand why HTS will not easily displace LTS from present applications. By far the biggest present market is for magnetic resonance imaging magnets, which all use LTS conductors, partly because LTS Nb-Ti conductors are so good and cheap, and partly because their sophisticated cryostat design demands only an annual helium filling. HTS current leads, the first killer application of HTS, actually make the task of replacing all LTS conductors in present applications unnecessary, for well-designed HTS current leads can reduce the heat leak to liquid helium by about 90 per cent, permitting heliumfree ('dry') electromagnets wound with LTS wire. Widespread HTS applications await better, cheaper conductors for power cables, transformers, motors and other electric power applications.

Recent HTS conductor progress has been impressive, but a handbook like this shows that LTS conductors are still far from being counted out in the continued drive for more superconducting applications.

David Larbalestier is in the Applied

Superconductivity Center, University of Wisconsin, 1500 Engineering Drive, Madison, Wisconsin 53706, USA.

\section{When the boat comes in}

\section{Marine Biodiversity: Patterns and Processes}

edited by R. F. G. Ormund, J. D. Gage and

M. V. Angel

Cambridge University Press: 1997. 442pp.

$\mathfrak{E} 50, \$ 74.95$

\section{LindaMedlin}

Biodiversity is the environmental concern of the 1990s and will remain a concern into the next millennium, with ecosystem destruction and species extinction now recognized on a global, epic scale. For some time, marine biologists and ecologists have stressed that far less is known about the biodiversity of marine environments than that of terrestrial ecosystems. Indeed, the processes of speciation and dispersal in the two ecosystems are likely to be vastly different. Marine Biodiversity helps to redress the balance by explaining major patterns of diversity in the marine environment.

Chapter subjects range from diversity in

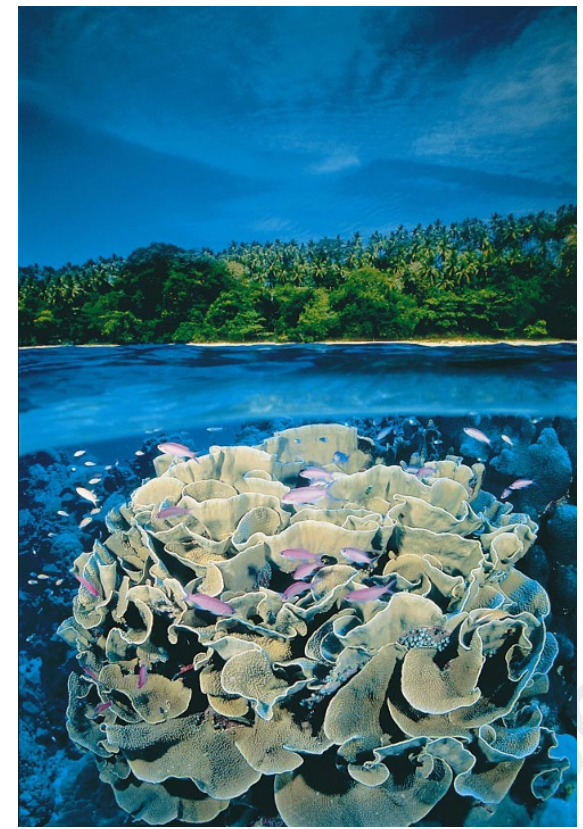

Fragile beauty: Anthias pseudanthias tuka coral in the waters off Bunaken Isle, Indonesia.

the upper waters of the open sea (the pelagic) to that in shallow seas, and from the bottom of deep seas (the benthic) to coral reefs. The writers consider how historical, biogeographic and oceanographic factors have structured biodiversity at the $\alpha$ (local habitats), $\beta$ (between habitats) and $\gamma$ (regional) levels, and how this biodiversity is maintained and should be managed. Of special interest is the evidence for nutrient availability controlling tropical Indo-Pacific benthic community diversity; for large-scale current disturbances affecting deep-sea diversity; and for the control of diversity in estuaries by coastal geomorphology. Notably absent, however, are any chapters devoted to phytoplankton or macro-algal diversity, a common oversight in studies on biodiversity.

Commonly held ideas about marine biodiversity, such as the existence of large randomly breeding populations, are gradually loosening their hold. Molecular genetic studies of marine populations continue to reveal small genetically effective population sizes, making more careful management of marine populations essential. Gradients in marine diversity, especially latitudinal ones, are repeatedly called into question for certain geographical areas, such as the southern hemisphere, and for certain ecosystems, such as the shallow to deep sea benthos. Because these themes are discussed in several chapters, there is some overlap in the materi$\mathrm{al}$, and more cross-referencing could have been made. Historical (geological) legacies play an important role in shaping biodiversity and should be used more to counter current views of the predominance of latitudinal gradients in the marine environment.

No book on biodiversity would be complete without a discussion of molecular genetic variation in populations and how this can be interpreted in terms of local adaptation and isolation, which could lead to speciation. The lack of resolution in population boundaries suggested by allozyme data is continually contrasted to that recovered with sequence data, so problems associated with identifying cryptic species still persist. With few hints of morphological variation in some species, small amounts of genetic variation tend to be overlooked. These differences are now being appreciated, thanks to the rapid increase in the number of sibling species recognized in the marine environment.

The Baltic is an example of a low-diversity area, and studies in this water body provide the clearest evidence for how ecosystem function can be threatened if a major functional group is eliminated from the community. Ecological functioning of biodiversity is explored in the contribution by G. C. Ray et al., who propose a landscape pattern approach from the ecosystem down to the species level. They predict that the decline or removal of a species will influence both total biodiversity and environmental conditions because feedback mechanisms are removed. Clearly, this would have far-reaching effects for ecosystem management. Although, as pointed out by J. S. Gray, the 'hotspots' of greatest diversity have been targeted for monitoring by international agencies, these are not the areas that are subject to man's greatest influence.

Mariculture also has an effect on biodiversity, but is not often highlighted. Its impact on biodiversity can be both beneficial and harmful, so careful planning is vital.

The overriding themes emerging from this book are that we still know very little about the factors controlling marine biodiversity in certain ecosystems, and far less about the mechanisms controlling genetic diversity. However, because of the major influence that the marine ecosystem has on our global climate, and because of the heavy reliance man has on marine resources, the impacts of disturbances on marine biodiversity should not be underestimated.

Most authors call for more quantitative data to assess biodiversity at all levels in the marine ecosystem before effective management can be implemented, but we mustn't wait too long. Species are disappearing at an alarming rate. The book even suggests that perhaps we need some catastrophe just large enough to persuade governments and peoples to look at ocean management in a more radical fashion, rather than simply for the protection of certain species, the disposal of particular wastes, or the study of unusual phenomena. Effective ocean management to sustain and protect marine biodiversity is a global issue that is here to stay.

Linda Medlin is in the Department of Biological Oceanography, Alfred Wegener Institute, Am Handelshafen 12, D-27570 Bremerhaven, Germany. 